\title{
Multimedia Presentations in Civil Engineering Courses Using Mathcad
}

\author{
D. M. Griffin, Jr. \\ Louisiana Tech University
}

\section{Background}

I first began using Mathcad 2.0 in the mid to late 1980's. In 1989 I used it as part of an experiment in team teaching an introductory calculus course with a faculty member from the mathematics department. Since that time, my use of Mathcad has increased to the point where I use it for all aspects of all the courses I teach (notes, problems etc.). I currently use Mathcad 6.0+ as the basis for all course materials in an applied numerical methods course, engineering dynamics, applied water chemistry, air pollution, environmental engineering (three different courses) and contaminant transport. I have (unintentionally) reached the point where I no longer maintain course notes or problems on paper. At last count I had approximately 13,000 stored Mathcad files, nested seven subdirectories deep in places on my computer. I also have some experience with other mathematics packages such as Derive, T K Solver, and Mathematical.

\section{Why Mathcad?}

It is generally acknowledged that Mathcad is not the most mathematically powerful software package available; however, it is one of the easier applications of this type to learn to use. Mathcad is oriented toward actual "number crunching" rather than symbolic manipulation as are other applications, although it has substantial capability in this area. I have found that the power available in Mathematical, for instance, is offset by the difficulty of using it and is rarely needed in most engineering computations. In addition, the type of problems I cover are not usually amenable to analytical solutions for which symbolic solvers are particularly useful.

The Mathcad characteristic which originally attracted me was the capability of producing document(s) which look very much as they might if written by hand. With Mathcad, equations and mathematical operators are easily identifiable and the user is not constrained in the placement of text or equations, the two can be interspersed as needed. As a result, documents can be prepared which are understandable to persons who have never used the software. This means that Mathcad can be used as the primary presentation medium in a classroom even though most students have never used it. Conversely, students can be expected to produce clear, articulate assignments that can be easily understood by others. I am not aware of another mathematics-oriented software package which allows such flexibility.

A second important capability of Mathcad is the ability to produce graphs quickly and easily. Being able to present technical material and problem solutions in a graphical format seems to dramatically enhance the student's ability to grasp a concept rather than simply get a correct answer. As an example, consider an undergraduate dynamics course Most problems in currently available dynamics texts are posed in such a way as 
to require the student to produce a single numerical answer, e.g., what is the particles. velocity at $\mathrm{t}=6$ seconds? I find that far more enlightening results can be gained from the same problem if the particle's velocity is plotted and examined over a relevant time range. The student can then "see how the system works." I once had a student tell me that "trying to grasp the concepts demonstrated in most dynamics problems by computing a single numerical answer is like trying to figure out the game of baseball by watching the right fielder through a hole in the fence." I agree. As discussed below, recent versions of Mathcad have dramatically enhanced the capability of presenting numerical results in various graphical formats.

\section{New Mathcad Features}

I use the most recent version of Mathcad, Mathcad 6.0+. Also, the Department of Civil Engineering at Louisiana Tech has a computer laboratory equipped with a 15-seat site license for 6.0+. In addition, a significant (and increasing) percentage of our students have their own personal, and sometimes even legal, copies of 6.0+ or earlier versions of Mathcad. Students are encouraged not to use pirated copies of Mathcad.

A short listing of the features new to $6.0+$ which I find most useful, together with a brief description of each, is given below.

- Mathcad 6.0+ is Windows '95 compatible. The most significant benefit is the ability to use longer, more descriptive file names. This is important since I have approximately 13,000 Mathcad files. Finding a particular one is often difficult, regardless of the subdirectory structure used to arrange them. However, new users should be aware that Mathcad (not Windows '95) imposes a 78-character path length limitation on all files. This, in effect, limits the number and length of the name of subdirectories. Files with paths longer than this are saved with abbreviated file names or not at all. More importantly, the user is not made aware of this at the time and risks losing files. This is a potentially serious problem and it is hoped that it will be remedied soon.

- As with earlier versions of Windows and Mathcad, the Windows ' 95 environment allows cutting and pasting of drawings from Paint, an improved version of the windows utility Paintbrush. This allows the user to draw and import the necessary free body diagrams, schematics and flow diagrams to complete and enhance solutions. In addition, plots from Mathcad can be taken into Paint, enhanced for final presentation and returned to Mathcad. At this point, however, they become a bitmapped graphic and are no longer "live."

-A major criticism of previous versions of Mathcad was the inability to construct a looping structure. The newest version allows the user to actually program within the Mathcad environment, including several types of looping structures. This opens up entirely new classes of problem solutions for which Mathcad can be used. As an example, I use an animation of the advection dispersion equation obtained by repeated solution of the finite difference equations using an implicit (Thomas algorithm) solution technique. Prior to 6.0+, I had developed a manual loop for such solutions using the "READPRN" and "WRITEPRN" statements. This loop could be made to repeat automatically by saving the necessary keystrokes as a macro in the recorder utility in Windows; however, this approach was tedious and necessitated moving between Mathcad and Windows. Now, the same thing can be done quite easily and entirely within Mathcad.

- Any portion of a document can be animated. An equation or set of equations can be solved repeatedly and the solutions displayed sequentially on the computer screen. This allows the user to actually see the solution of an equation as it progresses through time and space. For example, I use animations to demonstrate the difference in the nature of convergence between the bisection and false position methods for solving transcendental equations. A version of this file is provided as Attachment 1. 
- Mathcad 6.0+ has improved matrix utilization capabilities. Any element within a vector or matrix can itself be a vector or matrix. This allows for very efficient storage of large quantities of data or results, For example, a set of linked equations may be solved repeatedly and the results saved in a single vector, each element of which is also a vector. Attachment 2 utilizes this property after solving a titration problem in chemistry.

\section{Current Mathcad Usage}

In the following paragraphs, I will describe several of the courses in which I use Mathcad as the primary means for presenting information to the class and the multimedia variations used to make the presentations. Grades in the undergraduate courses are generated from daily quizzes and daily homework. Grades in graduate courses are generated from daily quizzes, homework and class participation.

- C.E. 291--Applied Numerical Methods. Text, Numerical Methods for Engineers, Chapra and Canale (McGraw Hill), 1988. Students are required to use Mathcad for the majority of assignments in this class. Even though the secant method is available within Mathcad (the root function) as a root finder for single equations, students are required to use the programming capability of $6.0+$ to construct algorithms for the bisection, false position and Newton Raphson methods. In their algorithms, the sequence of estimated roots generated during convergence is stored and either plotted or animated, allowing the students to see how convergence proceeds in each method.

Mathcad is also used in this course for matrix manipulations, simple finite difference solutions and numerical integration and differentiation, I simulate random variations in empirical problem parameters, e.g., drag coefficient, during simple finite difference solutions using a variety of available random number generators.

Results are usually presented as overheads accompanied by handouts. On occasion I have used a computer and overhead projector in the classroom. Mathcad files are also accessible from the departmental computer network and periodically students are required to obtain files from the Mathcad home page on the World Wide Web.

- C.E. 314--Environmental Engineering. Text, Introduction to Environmental Engineering, Davis and Cornwell (McGraw-Hill), 1991. This course covers some very basic elements of hydrology, waste treatment, water treatment and solid/hazardous waste. Mathcad is quite useful in allowing problems to be solved for a range of values of the independent variable. Results can be plotted quickly and easily. For example, overheads are used and handouts provided showing the resulting $\mathrm{pH}$ as a function of sodium hydroxide $(\mathrm{NaOH})$ dosage for the precipitation of magnesium hardness from potable water. A similiar problem examines the precipitation of nickel from a hazardous waste stream. Graphical presentation of such results is quite benefical to engineering students who may not have enough experience with chemistry to have developed a "feel" for what to expect. In addition, because chemistry problems often produce results varying over many orders of magnitude, log-log or semilog axes may be selected for easier viewing.

A variety of statistical distributions are available which are used for examining hydrologic as well as laboratory data. Last year, in the laboratory portion of the course, each student determined the $\mathrm{pH}$ of a sample of tap water. Each student was required to compile the results, which included about 40 measurements. Using Mathcad, the students then plotted a histogram and graphically compared it to a normal distribution with the same mean and standard deviation. In this instance, with Mathcad's common statistical function readily available, it requires relatively little time and effort to develop exercises which "connect" courses in the students' minds. 
-E.M. 203--Dynamics. Text, Engineering Mechanics - Dynamics, Rogers and Jong (Saunders Publishing Co.), 1991. Students are not required to use Mathacd in this course; however, it is assumed they have the necessary tools to work the problems assigned which, with increasing frequency, are "enhanced versions" of standard textbook problems requiring numerical solutions and/or manipulation and analysis of data.

In addition to the plotting capabilities discussed earlier, Mathcad provides a number of tools which make it easier to solve problems involving actual data. Functions such as splines, linear and non-linear regression, and statistical distributions are available. I sometimes use splines as a means of placing a smooth curve through data points. Textbook problems rarely require such sophistication but this is a good opportunity (and takes very little time) to qualitatively demonstrate to students the value of using what may otherwise remain a mysterious mathematical abstraction. A few students in the class will pick up on splines and begin using them. Thus, I also provide a handout (done in Mathcad) to those who are interested, describing the various types of splines and potential pitfalls of incorrect spline usage.

In past years, material in this course has been presented entirely on overheads. This year a combination of overheads and handouts is being used.

-C. E. 531--Contaminant Transport. Text, Principles of Surface Water Quality Modeling and Control, Thomann and Mueller (Harper and Row), 1987. Students are required to use Mathcad for all homework assignments. The last time I taught this course I used a computer with an attached overhead projector almost entirely as the method of presentation. Not only could I present the material I had prepared but students could, and sometimes were required to, bring in their assignments on disk for viewing and discussion in class. Files were also placed on the departmental computer network for student access. Because this class is usually small and populated by persons knowledgeable in Mathcad and computers, it functioned with a great deal of interactivity, not only between the student and me, but among the students themselves.

Advanced environmental problems usually contain a number of empirical variables whose values can vary, thus affecting the solution. However, as with dynamics, most textbook problems are written so as to require a single answer. With Mathcad, problems could be "enhanced" and students were expected to perform sensitivity analyses to determine which variable(s) were most important in a particular problem. Such analyses can help determine where to expend the limited resources available for problem solution.

-C.E. 410--Air Pollution. Text, Air Pollution, Its Origin and Control, Wark and Warner (Harper), 1981. The 3-D surface and contour plots in Mathcad are excellent for visualizing the various analytical solutions of the Gaussian plume model presented in most air pollution texts. Students perform sensitivity analyses to get a feel for the relative significance of atmospheric stability, emission rates and wind speed on resulting pollutant concentrations in the atmosphere.

Material for this course is usually presented using a combination of overheads, handouts and computer projection. Students are sometimes required to present solutions in Mathcad on disk for viewing by the class.

-C.E. 550C--Water Chemistry. Text, Water Chemistry, Snoeyink and Jenkins (John Wiley \& Sons), 1980. For several years I taught this course using the graphical, master variable approach described in most applied chemistry texts. Simply put, this requires plotting a set of curves relating the concentration of each constituent to the aqueous $\mathrm{pH}$. Assumptions regarding the relative amounts of constituents present are made in order to eliminate unknowns. A final solution is obtained and the assumptions are verified, or the process is repeated with different assumptions. This approach is apparently used in order to make the mathematics 
tractable. Unless simplifying assumptions are made, a numerical solution is required. The problem with this approach is that few engineering students have the chemistry background to know which approximations are reasonable. As a result, the entire process becomes quite confusing.

Mathcad contains several algorithms for solving sets of linear and/or nonlinear equations. Because of this, the entire approach, with attendant assumptions, becomes largely unnecessary. Independent mass and charge balances can be written along with a proton condition and constituent equilibrium expressions to obtain a set of equations with an equal number of unknowns, which can then be solved simultaneously. I find engineering students to be more comfortable with this approach. The entire process can be repeated as necessary to demonstrate the interdependence between species concentrations and $\mathrm{pH}$. I normally develop master variable diagrams from my results for presentation in class, and have the students do the same. Because the procedure used to solve the equations is numerical, there is no guarantee that the solution is correct. Thus, students are cautioned to always substitute the solution vector back into the governing equations as a check.

\section{Problems, Solutions and Concerns}

Computer software, including Mathcad, is not a panacea. Any new technology brings with it problems which are usually not immediately obvious. Several of the concerns of the faculty in the Department of Civil Engineering, including myself, with respect to Mathcad and multimedia presentations are described below.

The primary purpose of C.E. 291 is to introduce students to elementary numerical methods and try to show them how such methods are an important tool in the solution of many different types of engineering problems. Given this fact, I personally find that I am able to introduce students to numerical methods faster, easier and with far less frustration using Mathcad than with FORTRAN, BASIC or C. Recently, the department --in an effort to reduce the total number of hours in the program--decided to no longer require students to take a programming language. Other than a freshman course where students are introduced to several types of computer applications, Mathcad, taught in C.E. 291, is now the only required computer application. Students are encouraged, however, to take a programming course as an elective later in the curriculum. This was not an easy decision and may be revisited.

Using overheads and handouts as the primary means of disseminating information can be expensive. I provide a minimum of one handout per class period for each course I teach. Handouts average around five pages in length. In addition, I use probably an average of three or so overheads per class, per course. My handouts tend to be lengthy because I can easily produce both an analytical and numerical solution even for challenging problems. I also provide multiple plots where appropriate and substantial explanation and discussion including questions relating to each problem. My students have come to refer to this as "beating a problem to death." In some instances multicolored overheads are necessary, which cost $\$ 0.50$ to $\$ 1.00$ each. Course enrollments range from a minimum of five in graduate courses to more than 40 in E.M. 203 and C.E. 314.

The use of computer screen projection in the classroom may eliminate some of the expense described above. However, I find that the quality of the projected images using the equipment available is not very good. Colors are often lost and images fuzzy. It should also be noted that when using overheads or computer projection, rather large type sizes are required. I use 12 to 16 point Arial depending on the size of the classroom. Even when I use computer projection, the students find handouts to be very useful.

Because the material being covered is often prepackaged, I do not spend large amounts of time writing/drawing on or erasing a blackboard. Thus, a substantial amount of additional "active" time is available 
during class. Initially, I used this time to cover additional material. I soon found that even with overheads, handouts, computers, etc., students were becoming frustrated by their inability to keep up. Regardless of the method of presentation, it takes time for material to be absorbed. As a result, I had to modify the way I conduct class. Rather than simply lecturing more, I now use the time available to require the students to do a great deal of the talking in class, even in large classes. They sometimes find this difficult. At the beginning of each quarter, classes (particularly undergraduate classes) are often punctuated by periods of deafening silence. However, this usually lasts only a short while. Once they are comfortable, I estimate that students do $40 \%$ of the talking in my larger, undergraduate classes and $90 \%$ in the smaller, graduate classes. I find this beneficial because their comments, questions and discussion allow me to hear what they do and do not understand, which, by the way, almost never coincides with what I think they should or shouldn't understand. I am still able to cover at least as much as I did under the old blackboard/lecture system.

As a result of the additional tools afforded by Mathcad, the types of problems I assign and the types of analyses requested have changed, as indicated previously. Originally, in courses where students were required to use Mathcad or other software, I became concerned that they may simply be "pushing buttons" while not really understanding the material. As a result, students are required to provide correct, understandable (to others), written explanations with their calculations, which is easy to do with Mathcad. This requirement also arose as a result of my ongoing research, consulting and forensic experiences (mistakes) and has since become a general requirement in all my classes. The stated purpose of written explanations is to convince the person doing the grading that the students are not simply pushing buttons, but actually understand what they are doing and why they are doing it. As a result, a student can have a correct numerical solution but be penalized because of an inaccurate or missing explanation. Most students don't like this and I spend considerable time trying to convince them it's necessary. Surprisingly, I find that students with high grade point averages are often the most resistant. They often feel that a written explanation in addition to a correct numerical solution is redundant.

Because of the somewhat subjective nature of their grades, students are encouraged to adopt a constructive, articulate and adversarial approach to grades perceived to be unfair. Addressing these concerns is time-consuming for me and the paper graders and places a great deal of pressure on the graders, particularly international student graders. However, I believe it is an excellent real world exercise for both groups.

While the computer and Mathcad have dramatically increased my capabilities while saving countless preparation hours, I have (unintentionally) reached the point where I no longer maintain problems or course notes on paper. For instance, I don't possess a single dynamics problem or set of dynamics notes on paper. For my other courses I have notes prepared years earlier which I use, but I no longer make notes or do problems on paper for any of them. As a result, I am totally dependent on the computer. I have installed a Colorado 1400 internal tape backup and do at least a modified backup every day and a total backup once a week,

As the capabilities of Mathcad and my understanding of them improve, I seem to be continually reworking the files I have, in addition to producing new ones. As a result, I am constantly discarding existing handouts and transparencies and replacing them with "new and improved" versions. This can get to be expensive. Also, I can never seem to settle into a consistent pattern with respect to how I convey material to a class, which gets a little frustrating at times to me as well as to the students.

\section{Summary}

Because of the concern that students using Mathcad or other software may unintentionally substitute correct key stroking for actual understanding of the material, clear, concise written explanations are required 
with all problems. A considerable amount of faculty/grader time and effort is expended in grading problems and accompanying explanations. In general, students do not appreciate this requirement.

- The use of Mathcad has dramatically increased my capabilities while reducing the time required to prepare classroom materials. I can now easily incorporate additional mathematical and statistical techniques in my problem solutions without significant additional preparation time. I can also enhance textbook problems and solutions to make them more realistic. Material is presented in class using handouts, overheads and computer projection. Because I seem to be constantly updating files, the process can be expensive and frustrating. However, regardless of the method of presentation a certain amount of time is necessary to allow students to digest the material which ultimately limits the speed at which material can be covered.

\section{Biographical Information}

DIXIE M. GRIFFIN, JR. is a Professor of Civil Engineering at Louisiana Tech University in Ruston, Louisiana. He received the Ph.D. in 1979 from Virginia Tech. He teaches courses in environmental engineering, engineering mechanics and applied mathematics. In addition, Dr. Griffin has been involved in a variety of modeling projects at the U. S. by Corps of Engineers, Waterways Experiment Station, in Vicksburg, Mississippi. He is a registered professional engineer in Virginia, Louisiana, North Dakota, and the Province of Saskatchewan, Canada. 


\section{Attachment 1}

\section{An algorithm for the Bisection method showing convergence}

Introduction: The bisection procedure is a method for locating the roots of equations based on the fact that the equation changes sign as it crosses the $x$ axis. The method requires 2 initial guesses which result in functional values with different signs.

The average of the $\mathbf{2}$ guesses is computed and this value replaces one or the other of the original guesses depending on the sign of its functional value. This procedure is repeated until the root is attained with sufficient accuracy.

$$
\mathbf{x}:=.1, .21 . .1 .5
$$

This particular version of the worksheet allows students to explore the family of functions; $\mathbf{x}^{\text {“ }} \mathbf{- 1 \text { . }}$

The value of $\mathbf{n}$ has been set to $n:=10$ the user can change it as they wish to examine changes in convergence

$$
f(x, n):=x^{n}-1 \quad \text { equation to be solved, can be easily changed }
$$

$x_{\mathbb{I}}:=0.1 \quad x_{u}:=1.5 \quad$ initial guesses for upper, $x_{u}$ and lower, $x_{\mathbb{l}}$ values, these values must bracket a root

$$
x_{r}:=\frac{x_{l}+x_{u}}{2} \quad \text { compute a value of } x_{r} \text { to start the algorithm with }
$$

check to see if $X_{u}$ and $x l$ bracket a root. Guess again if product is $>0 \quad f\left(x_{u}, n\right) \cdot f(x, n)=-56.665$ when possible, plot equation for approximate location of roots

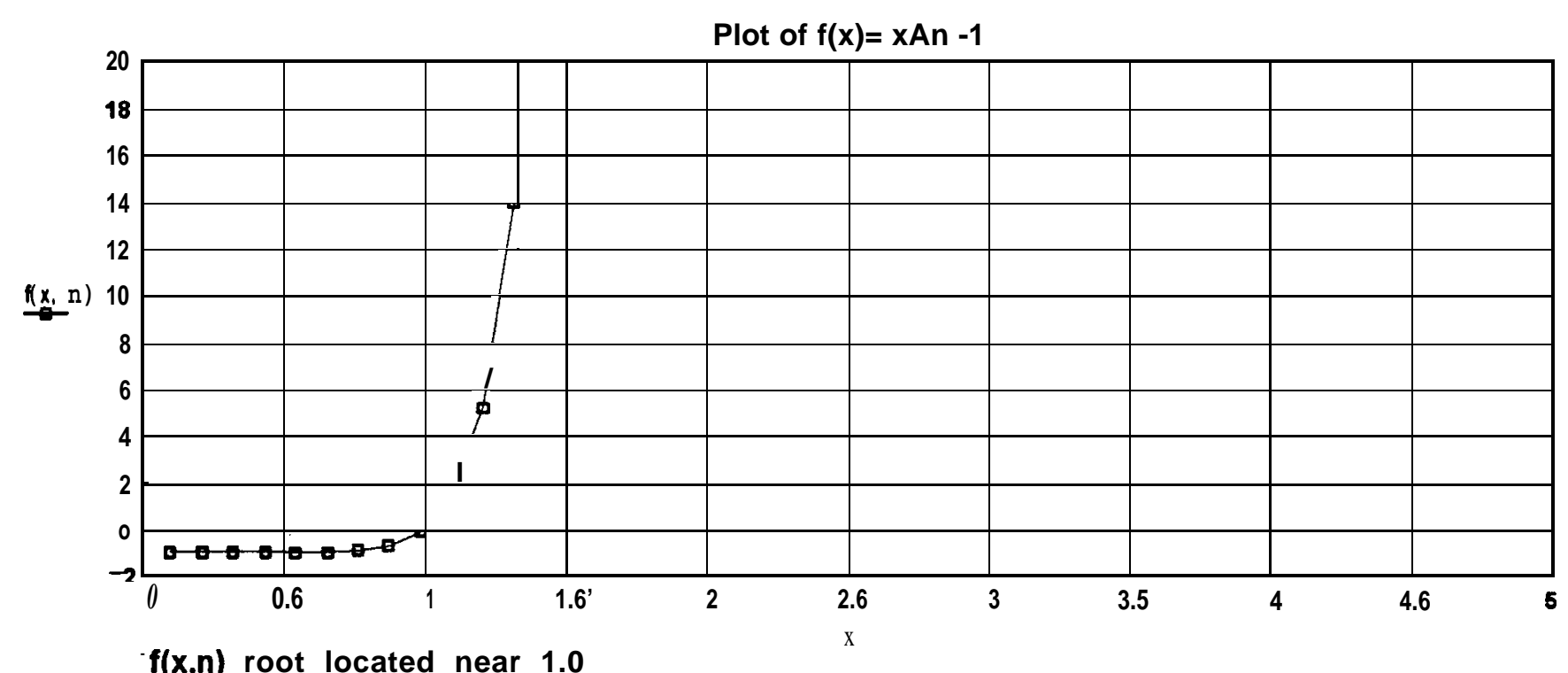

$f(x, n)$ root located near 1.0 


\section{Algorithm for bisection procedure which stores sequence of root estimates as well as} sequences of end points.

Mathcad programs are in the form of functions bisection_root, $\left.x_{u}, x_{1}\right)$. The items in the parentheses are the inputs to the function, in this case the upper and lower guesses.

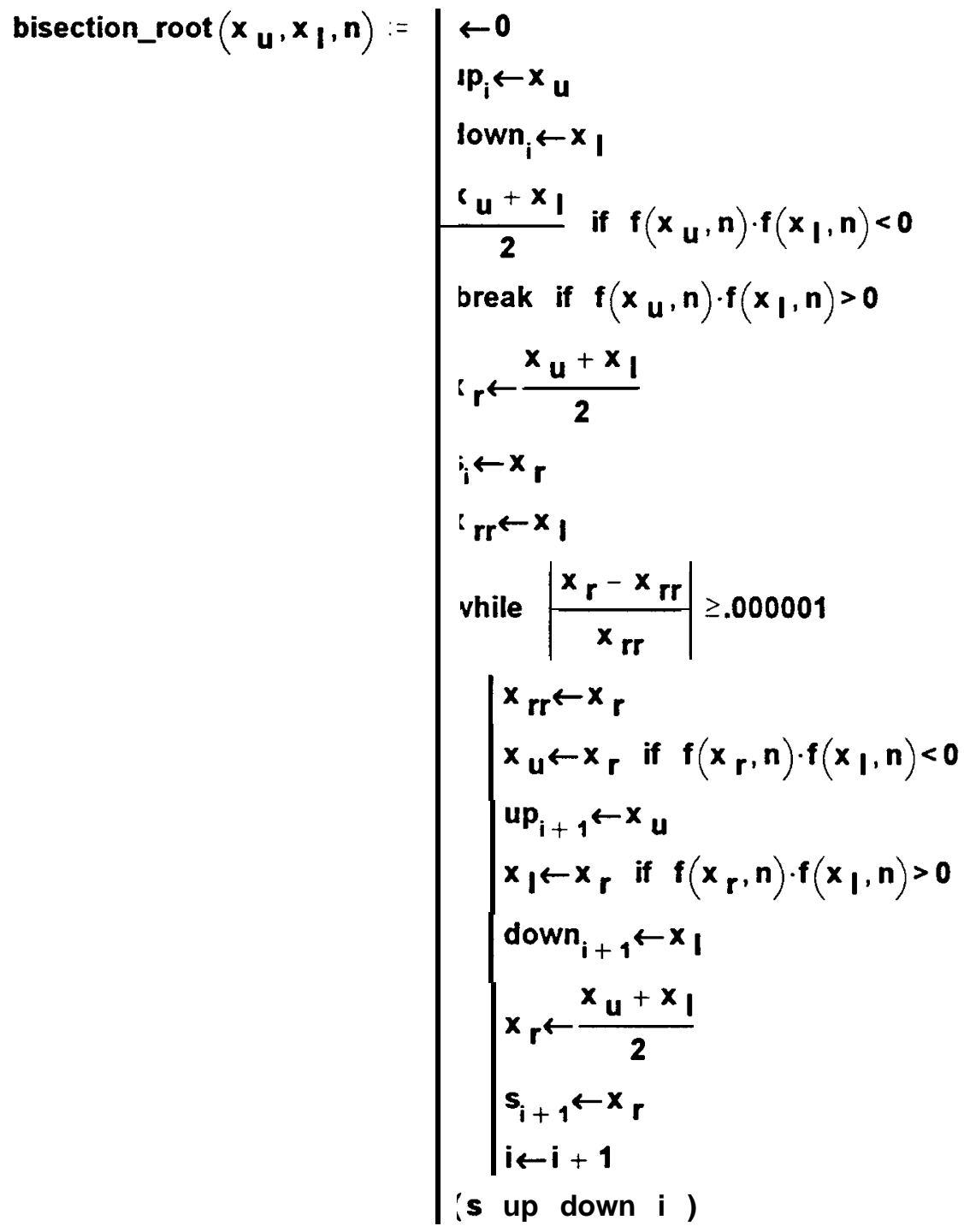

store initial guesses

in a vector

if $X_{u}$ and $x_{1}$ don't bracket a root stop

store initial and subsequent root estimates, $x_{r}$, in vector

establish stopping criteria based on approximate relative error. While loop is executed as long as condition is true

set current value of guess to old value, $x_{r r}$

determine which endpoint current $x_{r}$ replaces

compute next $x_{r}$ and store it in $\mathrm{s}$ vector

increment counter

create output vector wheres, up, and down are vectors. i is the last value of the counter 
Create a matrix containing the estimates of the root together with the upper end points for each iteration, lower end points for each iteration and the number of iterations completed

$$
\text { soln := bisection_root }\left(x_{u}, x_{l}, n\right)
$$

The outputs of the function are the values on the last line of the program:

soln $=(\{21,1\}\{21,1\}\{21,1\} 20) \quad \begin{aligned} & \text { This result says that the vector solution consists in turn of } 3 \text { one column, } \\ & 21 \text { row vectors and the single number } 20\end{aligned}$ each element of the solution matrix is itself a vector except for the value of $i$

root_estimate_seq uence upper_end_sequence lower_end_sequence

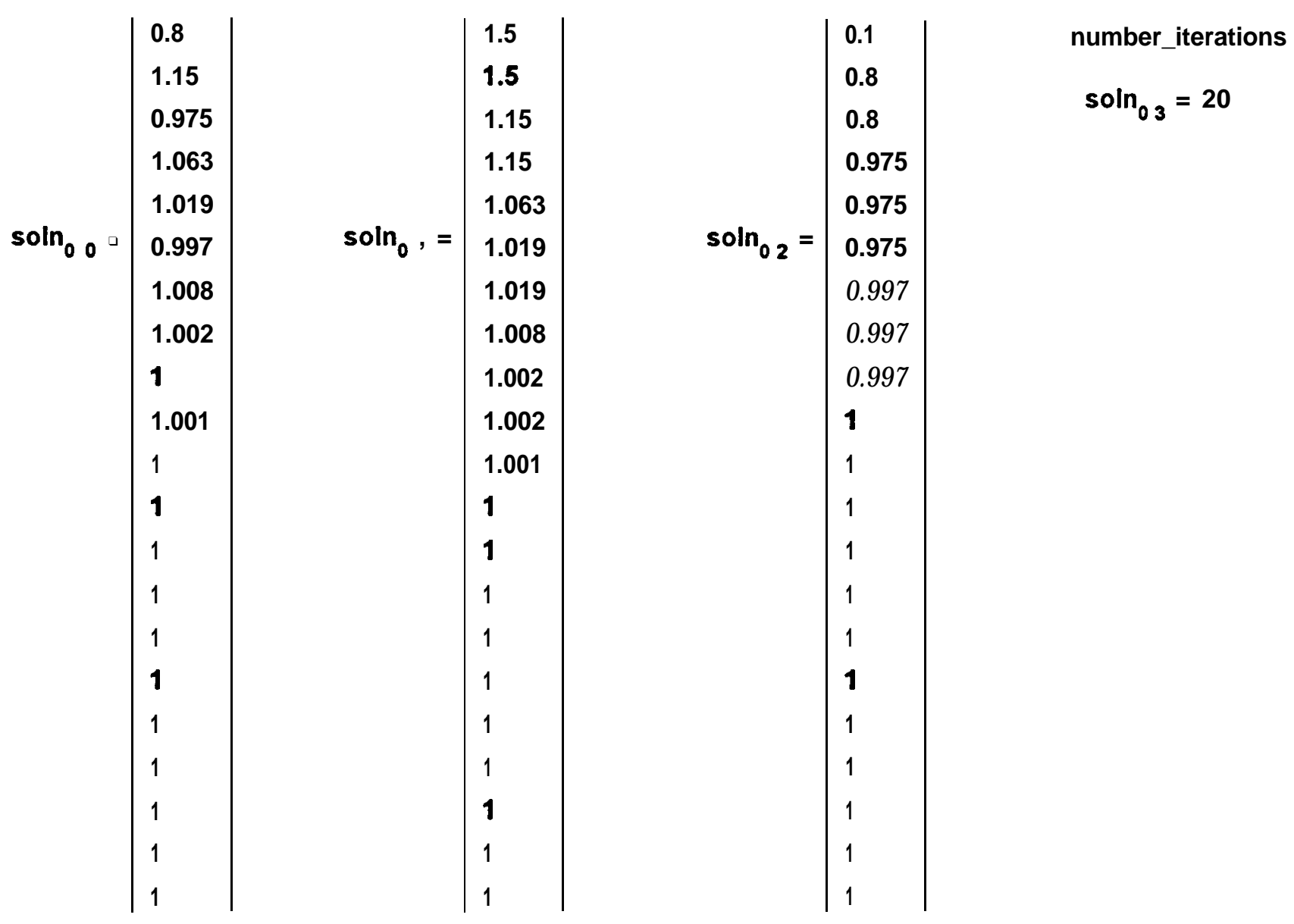


Rename each element in the solution vector for clarity; then plot the results

$$
\text { i : : }=0 . . \text { soln }_{0,3} \quad \text { counter }
$$

$x_{\mathbf{r}}:=\operatorname{soln}_{0,0} \quad x_{\mathbf{u}}:=\operatorname{soln}_{0}, \quad x_{\boldsymbol{I}}:=\operatorname{soln}_{0.2} \quad \begin{aligned} & \text { rename each column of the solution vector and } \\ & \text { plot them }\end{aligned}$

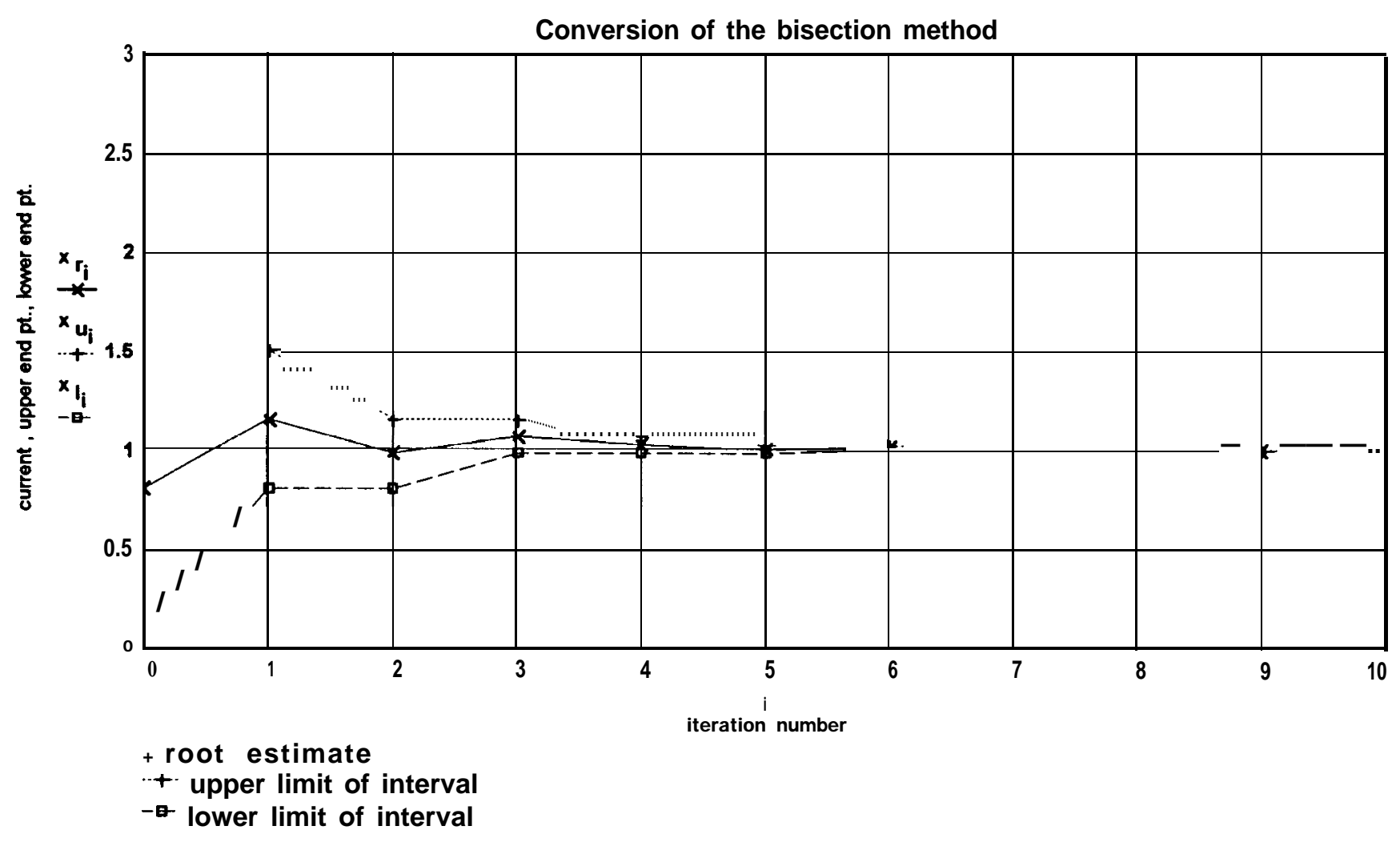

use the last root estimate to confirm that it satisfies the original equation

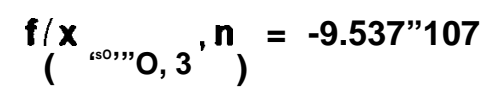

Discussion: note that the method involves both the upper and lower bound for the root in that both are pulled toward the actual root. The plot can be animated so that the student can watch the convergence process as it occurs. 


\section{Chapter 2- Carbon Dioxide Equilibria and their Applications}

-Mathcad file developed by D.M. Griffin, Jr., La. Tech University - DMG@engr.latech.edu

useful comments and criticisms welcome

REF: Carbon Dioxide Equilibria and their Applications, James M. Butler, Addison Wesley, 1982

This material is presented in an applied water chemistry course (graduate level) within the Civil Engineering curriculum at Louisiana Tech. Students are required to use Mathcad to do most problems.

The equilibrium concentration of $\mathrm{CO}_{2}$ in an open water system is given by Henry's Law, which is written as:

$$
\mathrm{CO}_{2}=\mathrm{K}_{\mathrm{H}} \cdot \mathrm{P} \mathrm{CO} 2
$$

where $\mathrm{CO}_{2}=$ molar concentration $\mathrm{CO}_{2}$

$K_{H}=$ Henry's Law constant, about 10-1.5 at $250 \mathrm{C}$. The value of $K_{H}$ decreases $\left(\mathrm{CO}_{2}\right.$ less soluble at higher temperatures, $10-17$ at $\left.50^{\circ} \mathrm{C}\right)$

$\mathrm{P}_{\mathrm{cO2}}=$ partial pressure of $\mathrm{CO}_{2}$ in atmospheres

\section{Hydration of CO. in water}

When $\mathrm{CO}_{2}$ dissolves in water it is hydrated to $\mathrm{H}_{2} \mathrm{CO}_{3}$. This reaction is slow (rate limiting) compared to the ionization reaction of $\mathrm{H}_{2} \mathrm{CO}_{3}$ to $\mathrm{HCO}_{3}$. At equilibrium the concentration of $\mathrm{H}_{2} \mathrm{CO}_{3}$ is only about $10^{-3}$ as large as $\mathrm{CO}_{2}$. In many texts $\mathrm{H}_{2} \mathrm{CO}_{3}{ }^{*}$ is taken to be the sum of the two components. Note that the $\mathrm{CO}_{2}$ concentration in an open system is dependent only on the partial pressure of $\mathrm{CO}_{2}$.

\section{lonization of dissolved $\mathrm{CO}_{2}$}

Once in solution $\mathrm{H}_{2} \mathrm{CO}_{3}$ ionizes to bicarbonate and carbonate according to:

$$
\begin{aligned}
& {\left[\mathrm{H}^{+}\right]\left[\mathrm{HCO}_{3}^{-}\right]=K_{21}[\mathrm{CO} 2]} \\
& {\left[\mathrm{H}^{+}\right]\left[\mathrm{CO}_{3}^{-}\right]=K_{22}\left[\mathrm{HCO}_{3}\right]}
\end{aligned}
$$

Note that the concentration of uncharged $\mathrm{CO}_{2}$ remains unchanged at constant partial pressure the carbon content, $\mathrm{C}_{\mathrm{T}}$ increases with increasing $\mathrm{pH}$ because of these equilibria.

$$
\begin{array}{ll}
\mathrm{CO}_{2}=\mathrm{K}_{\mathrm{H}} \cdot \mathrm{P} \mathrm{CO} 2 & \log \left(\mathrm{CO}_{2}\right)=\log (\mathrm{K} \mathrm{H})+\log (\mathrm{p} \mathrm{CO2}) \\
\mathrm{H} \cdot \mathrm{HCO}_{3}=\mathrm{K}_{\mathrm{a} 1} \cdot \mathrm{CO}_{2} & \log (\mathrm{H})+\log \left(\mathrm{HCO}_{3}\right)=\log \left(\mathrm{K} \mathrm{a}_{1}\right)+\log \left(\mathrm{CO}_{3}\right) \\
\mathrm{H} \cdot \mathrm{CO}_{3}=\mathrm{K}_{\mathrm{a} 2} \cdot \mathrm{HCO}_{3} & \log (\mathrm{H})+\log \left(\mathrm{CO}_{3}\right)=\log \left(\mathrm{K}_{\mathrm{a} 2}\right)+\log \left(\mathrm{HCO}_{3}\right)
\end{array}
$$


What is the $\mathrm{pH}$ when water and $\mathrm{CO}_{2}$ are in equilibrium at a partial pressure of $10^{-3.5}$ atmospheres? In most textbooks such problems are solved using a combination of assumptions regarding the final equilibrium composition and master variable diagrams for graphical solutions. Such a procedure assumes some familiarity with the system which a non-chemist may not have. Here we simply have to write as many independent equations as we have unknowns then use "solve block" to compute a solution vector.

$$
\begin{array}{lll}
P_{C O 2}:=10^{-3.5} & K_{H}:=10^{-1.5} & K_{a 2}:=10^{-10.3} \\
H:=10^{-7} & K_{a 1}:=10^{-6.3} & K_{W}:=1 \cdot 10^{-14} \quad \text { known values and guesses for unknowns } \\
\mathrm{CO}_{2}:=10^{-1} & \mathrm{OH}:=\frac{K_{W}}{H} & \mathrm{HCO}_{3}:=10^{-7} \\
& & \mathrm{CO}_{3}:=10^{-9}
\end{array}
$$

Begin solve block by typing "Given" in math mode and writing governing equations using symbolic equals (control $=$ ) signs. Initial estimates for unknowns required above.

\section{Given}

$$
\begin{array}{ll}
\mathrm{H} \cdot \mathrm{OH}=\mathrm{K} & \text { equilibrium expression for water } \\
\mathrm{CO}_{2}=\mathrm{K}_{\mathrm{H}} \cdot \mathrm{P} \mathrm{CO} 2 & \text { Henry's Law for } \mathrm{CO} 2 \\
\mathrm{H} \cdot \mathrm{HCO}_{3}=\mathrm{K}_{\text {a1 }} \cdot \mathrm{CO}_{2} & \text { equilibrium expression for bicarbonate }\left(\mathrm{HCO}_{3}\right) \\
\mathrm{H} \cdot \mathrm{CO}_{3}=\mathrm{K}_{\mathrm{a} 2} \cdot \mathrm{HCO}_{3} & \text { equilibrium expression for carbonate } \left.\left(\mathrm{CO}_{3}\right)^{\prime}\right) \\
\mathrm{H}=\mathrm{HCO}_{3}+\mathrm{CO}_{3} \cdot 2+\mathrm{OH} & \text { charge balance }
\end{array}
$$

A solution vector is defined to be the values of the unknowns computed below. Because a solve block is an iterative numerical solution the solution values should be substituted back into the governing equations to verify they are correct.

solution vector internal algorithm to find unknowns

$$
\left|\begin{array}{cc}
{ }^{H} \text { equil } \\
\mathrm{co} & 2 \text { equil } \\
\text { 'H } & \text { equil } \\
\text { ‘co } & \text { 3equil } \\
\mathrm{co} & 3 \text { equil }
\end{array}\right|:=\text { find }\left(\mathrm{H}, \mathrm{CO}_{2}, \mathrm{OH}, \mathrm{HCO}_{3}, \mathrm{CO}_{3}\right)
$$

When the cursor is moved away from the expression lack of error messages indicates a solution has been found 


$$
\begin{aligned}
& -H_{\text {equil }}=2.241 \cdot 10^{-6} \\
& -\log \left(\mathrm{H}_{\text {equil }}\right)=5.65 \quad \mathrm{pH} \text { of } \mathrm{CO}_{2}\left(\mathrm{P}=10^{-3.5}\right) \text { and water is } 5.65 \\
& \text { ALK }:=\mathrm{HCO}_{3 \text { equil }}+2 \cdot \mathrm{CO}_{3 \text { equil }}+\mathrm{OH}_{\text {equil }}-\mathrm{H}_{\text {equil }}
\end{aligned}
$$

Alkalinity is a measure of a solution's ability to resist a change in $\mathrm{pH}$ and is often used by environmental engineers. In this example the alkalinity is zero because alkalinity is defined to begin at the $\mathrm{CO}_{2}$ equivalence point. Adding or removing $\mathrm{CO}_{2}$ by changing the $\mathrm{P}_{\mathrm{CO} 2}$ (try it) does not affect the alkalinity, it's still zero.

$$
A L K=0
$$

As suggested above, input parameters to the problem can be changed and the solution recomputed quite easily. However, because the individual equilibrium concentrations computed in an applied chemistry problem can vary over many orders of magnitude it important that they be substituted back into the original equations to check their validity.

====EAnalytical solution

By manipulating the basic equilibrium equations we can express the concentration of carbonate and bicarbonate as a function of $\mathrm{pH}$ and the partial pressure of $\mathrm{CO}_{2}$

$$
\begin{gathered}
\mathrm{pH}:=2.14 \quad \mathrm{pH} \text { values of interest } \\
\mathrm{p}_{\mathrm{CO} 2}:=10^{-3.5} \quad \text { partial pressure of carbon dioxoide } \\
\log _{\mathrm{HCO} 3}(\mathrm{pH}):=-7.8+\log (\mathrm{P} \mathrm{CO})+\mathrm{pH} \\
\log _{\mathrm{CO} 3}(\mathrm{pH}):=-18.1+\log (\mathrm{P} \mathrm{CO} 2)+2 \cdot \mathrm{pH} \\
\log _{\mathrm{CO}_{2}}(\mathrm{pH}):=-1.5+\log \left(\mathrm{P}_{\mathrm{CO} 2}\right) \\
\log _{\mathrm{H}}(\mathrm{pH}):=-\mathrm{pH} \\
\log _{\mathrm{OH}}(\mathrm{pH}):=-(14-\mathrm{pH})
\end{gathered}
$$




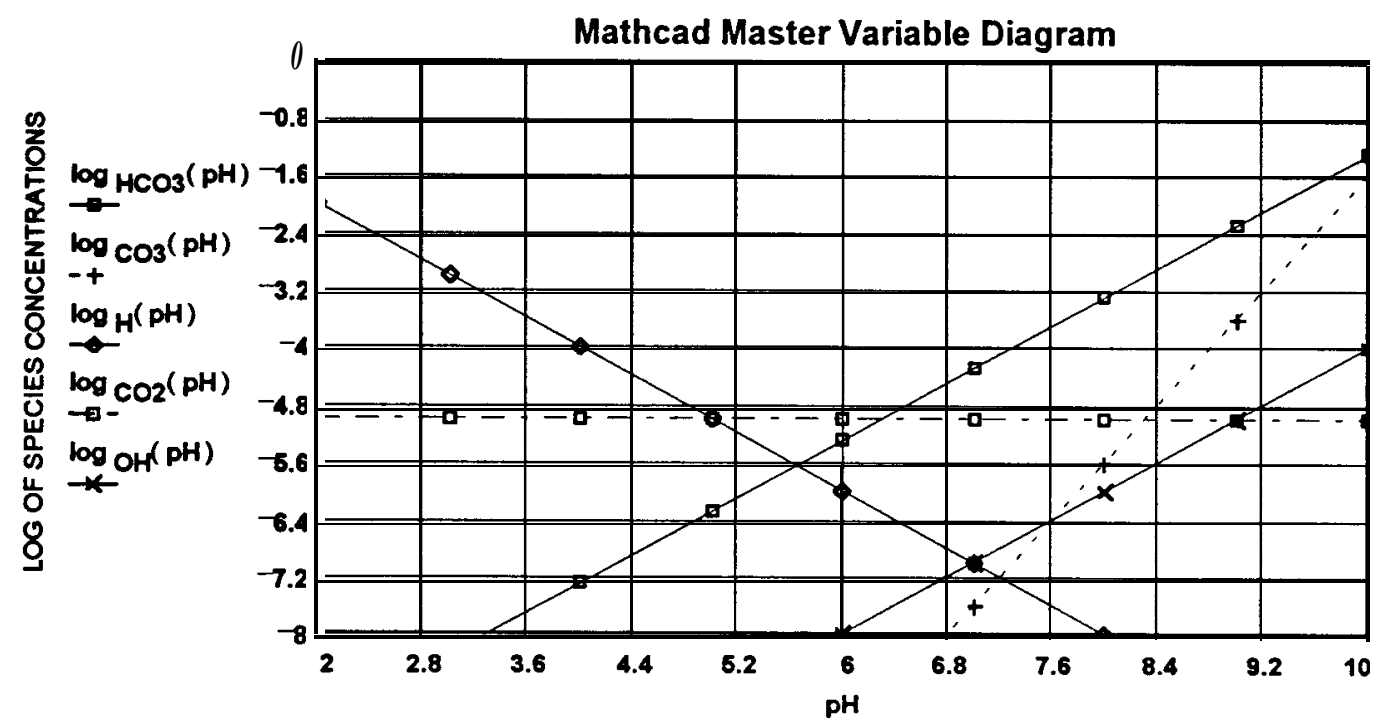

For a closed system (no gas phase) the analytical solution equations are:

$C_{T}:=10^{-3} \quad$ Total carbon concentration

$$
\begin{aligned}
& \mathrm{CO}_{2}(H):=\frac{C T .10^{2,3 H}}{K_{a 1} \cdot K_{a 2}+\left(K_{a 1} \cdot 10^{-H}+10^{-2 \cdot H}\right)} \\
& \mathrm{CO}_{3}(H):= \frac{C_{T} \cdot K_{a 1} \cdot K_{a 2}}{K_{a 1} \cdot K_{a 2}+K_{a 1} \cdot 10 \cdot H+\left(10^{-2 \cdot H}\right)} \\
& \mathrm{HCO}_{3}(H)= \frac{C_{T} \cdot K_{a 1} \cdot 10^{-H}}{K_{a 1} \cdot K_{a 2}+K_{a 1} \cdot 10^{\prime} H+\left(10^{-2 \cdot H}\right)} \\
& C_{T}(H):=C_{T}
\end{aligned}
$$

$H:=14,13.8 . .0 \quad$ evaluate a range of $\mathrm{pH}$ values... 

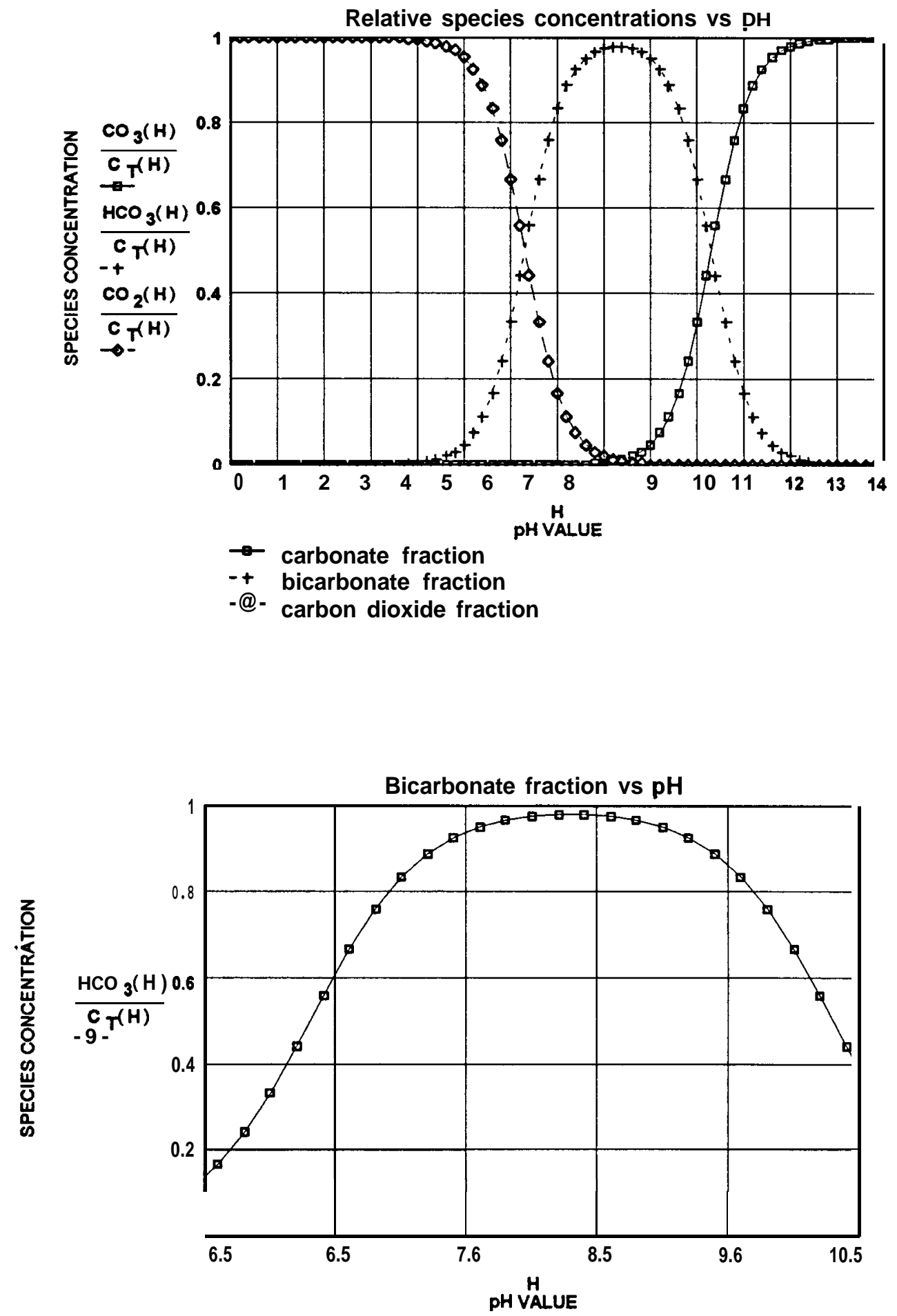

attach2.mcd 5 2/22/96

A S 1996 ASEE Annual Conference Proceedings 


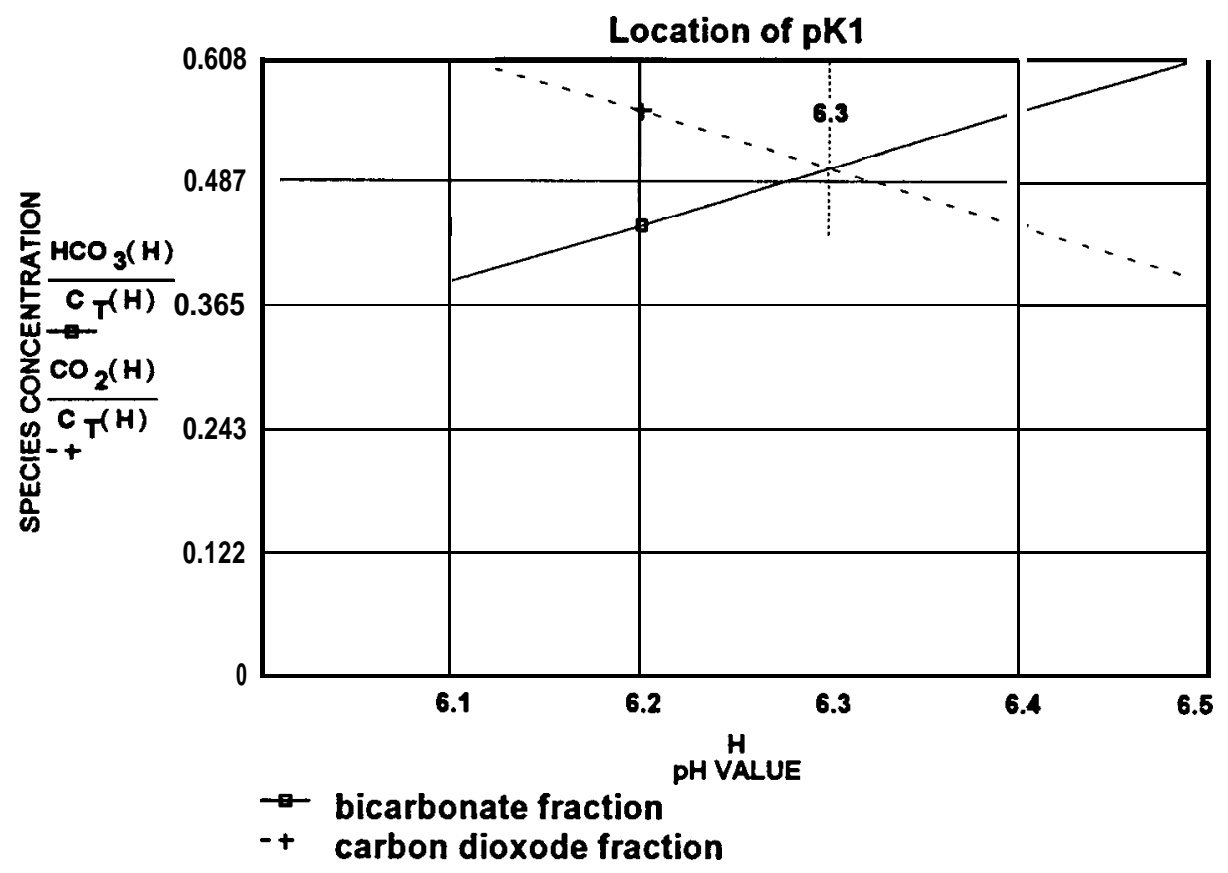

Using this type of worksheet students can test the effect of changes in variable values on the resulting equilibrium. They will also undoubtedly find out that initial estimates regarding the unknown quantities will affect the the ability of any numerical solution to obtain a correct solution, or any solution for that matter.

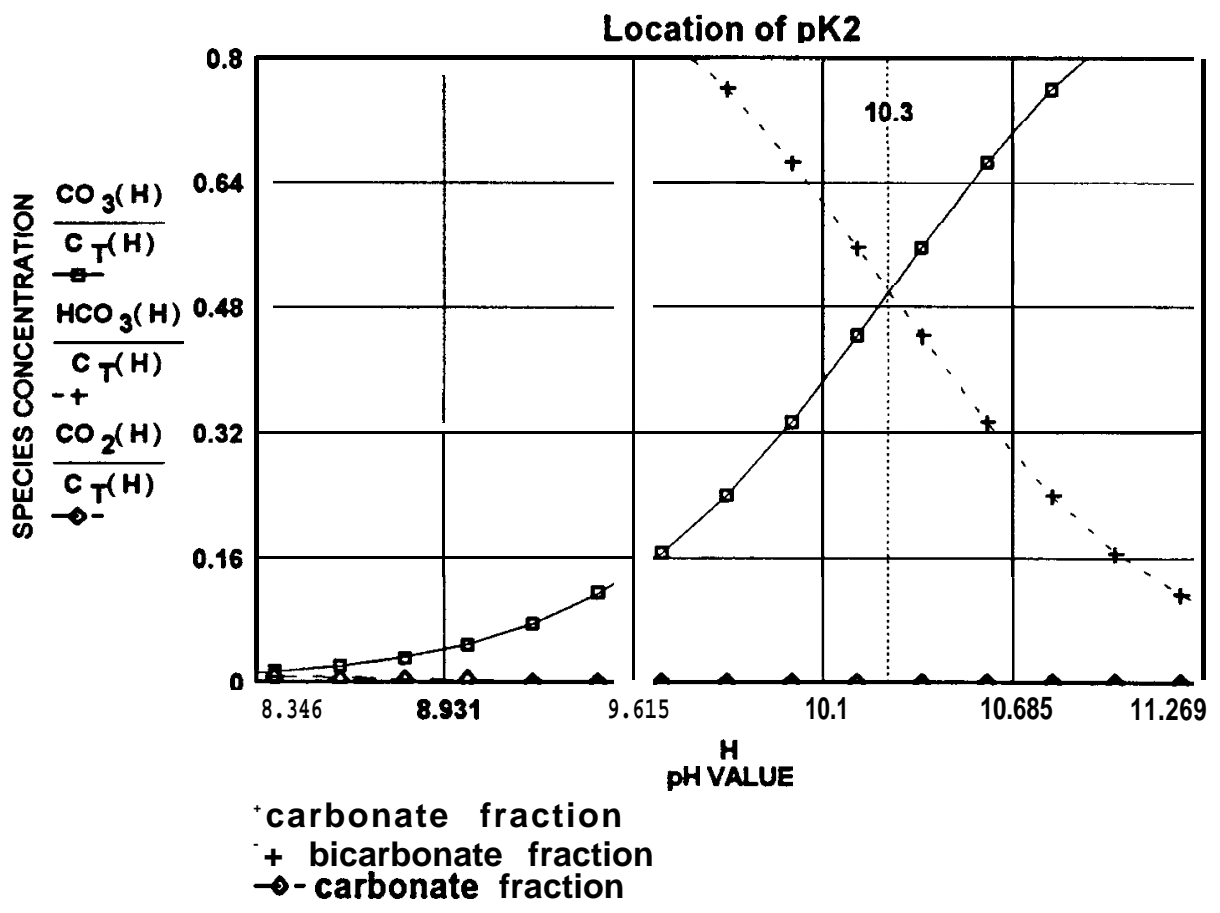

attach2.mcd 6 2/22/96 